\title{
ENSINO HÍBRIDO: UM ESTUDO DE CASO ACERCA DA APLICAÇÃO DA METODOLOGIA ROTAÇÃO POR ESTAÇÕES NO ENSINO FUNDAMENTAL
}

\author{
MATHEUS CARVALHO DO NASCIMENTO ${ }^{1}$, GEÓRGIA REGINA RODRIGUES GOMES ${ }^{1}$
}

${ }^{1}$ Universidade Federal Fluminense (UFF)

\begin{abstract}
RESUMO
O presente artigo, recorte da dissertação de mestrado do autor, buscou analisar possibilidades relacionadas à utilização das TIC enquanto tecnologias educacionais no processo de ensino e de aprendizagem através da metodologia Rotação por Estações, proveniente do conceito do Ensino Híbrido. O referido conceito compreende uma abordagem pedagógica que visa integrar as tecnologias ao cotidiano escolar, buscando alternância entre os momentos de ensino presencial e os momentos de ensino online, visando contribuir para a construção de um ambiente de produção de conhecimento mais interessante e rico. De modo a demonstrar a aplicabilidade da referida proposta metodológica no Ensino Fundamental, foi proposto e ofertado um curso de formação continuada para docentes do ensino fundamental da rede pública municipal de Santo Antônio de Pádua, Rio de Janeiro, apresentado as propostas norteadoras do Ensino Híbrido. Posteriormente foi realizada uma oficina com a referida metodologia, na disciplina de História, em uma turma do nono ano. A pesquisa, mensurada através de método qualitativo, demonstrou a relevância da utilização da metodologia em questão, uma vez que tal proposta despertou o interesse, além de favorecer e estimular a autonomia dos alunos, evidenciando a possibilidade de serem obtidos resultados positivos ainda que as escolas apresentem infraestrutura e equipamentos limitados.
\end{abstract}

Palavas-chave: TIC, Ensino Fundamental, Ensino Híbrido

\begin{abstract}
This article, a cut from the author 's dissertation, sought to analyze possibilities related to the use of ICT as educational technologies in the teaching and learning process through the Rotation by Stations methodology, derived from the concept of Hybrid Teaching. This concept includes a pedagogical approach that aims to integrate the technologies to the school daily, seeking a change between the moments of face-to-face teaching and the moments of online teaching, aiming to contribute to the construction of a more interesting and rich knowledge production environment. In order to demonstrate the applicability of the aforementioned methodological proposal in Primary Education, a course of continuing education was proposed and offered to primary school teachers of the municipal public network of Santo Antônio de Pádua, Rio de Janeiro, presenting the guiding proposals of the Hybrid Teaching. Subsequently, a workshop was held with this methodology, in History, in a class of the ninth grade. The research, measured through a qualitative method, demonstrated the relevance of the use of the methodology in question, since this proposal aroused the interest, besides favoring and stimulating the students' autonomy, evidencing the possibility of obtaining positive results even though the schools infrastructure and equipment.
\end{abstract}

Keywords: ITC, Elementary school, Hybrid teaching

\section{INTRODUÇÃO}

A escola contemporânea ainda apresenta, dentre suas características, uma estrutura de saber compartimentalizado, induzindo os sujeitos envolvidos no processo de ensino e de aprendizagem a compreender e assimilar os conteúdos de forma fragmentada, semelhante ao que lhes foi apresentado. Esta concepção de transmissão de conhecimento, baseada no modelo tradicional de ensino, acentua a dificuldade de contextualização dos saberes. Além disso, não há a contribuição necessária para a estruturação de um ambiente que estimule o desenvolvimento do raciocínio crítico e reflexivo; ao contrário, 
criam-se obstáculos que dificultam o desenvolvimento de conexões entre as disciplinas, minimizando as possibilidades de desenvolver vínculos entre as novas informações e a compreensão abrangente dos conhecimentos (OLIVEIRA, 2012).

As tecnologias de informação e comunicação (TIC) - compreendidas por Belloni (2005) como a junção ou fusão da informática, das mídias eletrônicas e das telecomunicações - estão presentes nos mais variados setores de nossa sociedade, sendo responsáveis, inclusive, por significativas mudanças sociais, econômicas e culturais. Na chamada "Era Digital" - especialmente a partir da década de 90 , com a popularização da internet - tais tecnologias, e em especial, o computador, tornaram-se cada vez mais presentes no cotidiano das pessoas. Atualmente, diante do facilitado acesso aos mais variados tipos de conteúdos e informações e da velocidade com que as conectividades ocorrem, espera-se que os sujeitos sejam capazes de "se conectar com o novo e acessar as informações no momento oportuno" (MOLIN, 2010, p.13).

O contato com tais tecnologias tem ocorrido cada vez mais cedo. Crianças e jovens, já acostumados à televisão, rádio e telefone, hoje se deparam com smartphones e tablets de última geração, jogos eletrônicos sofisticados, além de, por meio desses, terem acesso a intensa quantidade de dados e realizarem diversas interações na Internet, o que nessa faixa etária desperta a atenção e a curiosidade. O tempo, antes dedicado às brincadeiras lúdicas e à leitura, perde cada vez mais espaço para os entretenimentos que as tecnologias são capazes de oferecer, o que, por sua vez, influencia a cultura desse público - a linguagem, a escrita e demais formas de expressão (LOUREIRO; GRIMM; LUNARDI-MENDES, 2016). Consequentemente, os espaços frequentados por tais crianças e jovens, especialmente a escola, foram impactados, o que impulsionou a necessidade de reflexões acerca dos então consolidados processos e metodologias de ensino. Como afirma Jordão (2009):
Os professores se deparam nas salas de aula com alunos que convivem diariamente com as tecnologias digitais. Estes alunos têm contato com jogos complexos, navegam pela internet, participam de comunidades, compartilham informações, enfim, estão completamente conectados com o mundo digital (JORDÃO, 2009, p.10).

Diante de tal novo contexto, características e demandas da sociedade, o já referido modelo de ensino passou a ser questionado no sentido de não mais abarcar as necessidades desse novo público - dinâmico e ávido pelo novo. Nesse sentido, e mais recentemente, surgiram novas metodologias de ensino, onde as práticas pedagógicas se aproximam dos recursos tecnológicos.

\section{O ENSINO HÍBRIDO}

O conceito de Ensino Híbrido propõe uma abordagem pedagógica que visa integrar as tecnologias ao cotidiano escolar, buscando alternâncias entre os momentos de ensino presencial e os momentos de ensino online - onde os alunos têm acesso aos conteúdos, realizam atividades e exercícios utilizando as TIC (BACICH; NETO; TREVISANI, 2015). Nessa proposta as tecnologias são utilizadas com caráter pedagógico, complementando e enriquecendo o ambiente presencial, oportunizando novas interações e possibilidades para os alunos, buscando extrair o melhor de cada um dos métodos, objetivando a construção de um ambiente de produção de conhecimento mais interessante e rico. De acordo com Valente (BACICH; NETO; TREVISANI, 2015) apesar das diferentes propostas para realizar a combinação entre atividades presenciais e atividades realizadas a partir das tecnologias digitais, o Ensino Híbrido compreende uma significativa mudança no foco do processo de ensino e de aprendizagem, onde o modelo tradicional de transmissão de informação dá lugar ao aluno no centro do processo. Schiehl e Kemczinski (2017), ao explicitarem o conceito do Ensino Híbrido, salientam que não há uma determinação fixa para o ensino híbrido; 
a proposta engloba infinitas possibilidades de combinações, com o intuito de conduzir os alunos ao desenvolvimento de determinado conhecimento. Outros autores, porém, definem de forma mais objetiva este conceito. Streinert et al. (2016), por exemplo, afirmam que o Ensino Híbrido consiste em uma proposta para articular as tecnologias de modo que, através destas, seja possível melhorar a qualidade da educação e, consequentemente, potencializar o desenvolvimento dos alunos na construção de seu conhecimento

O Ensino Híbrido contempla duas formas principais que podem ser escolhidas e adotadas pelas instituições educacionais, de acordo com suas necessidades. A primeira delas é composta por mudanças mais radicais, que são implementadas, principalmente, por instituições com propostas mais inovadoras, que dispõem de maior poder de investimento e recursos. As instituições com estas características seguem uma proposta sem disciplinas, com projetos e metodologias ativas. Desta maneira os alunos são supervisionados pelos professores e aprendem de maneira individual e/ou em grupo, através de jogos, problemas, atividades e projetos. Neste formato é imprescindível respeitar as necessidades e o tempo que cada sujeito demanda para desenvolver suas habilidades e/ou conhecimentos (BACICH; NETO; TREVISANI, 2015).

O segundo modelo, menos disruptivo, não implica grandes investimentos financeiros ou a disponibilidade de uma grande quantidade ou variedade de recursos tecnológicos, pois a transformação mais relevante é em relação ao papel e postura de professores e alunos:

No caminho mais suave, elas mantêm o modelo curricular predominante - disciplinar - mas priorizam o envolvimento maior do aluno, com metodologias ativas, como o ensino por projetos de forma mais interdisciplinar, o ensino híbrido ou blended e a sala de aula invertida (BACICH; NETO; TREVISANI, 2015, p 29).
Por tratar-se de temática atual torna-se imprescindível a capacitação dos professores para que se torne possível sua aplicação, de modo adaptado à sua realidade.

Temos que cuidar do professor, pois todas as mudanças só entram bem na escola se entrarem pelo professor, ele é a figura fundamental. Não há como substituir o professor. Ele é a tecnologia das tecnologias, e deve se portar como tal (DEMO, 2008 apud ANDRADE, 2011, p.16).

O professor tem papel fundamental na relação que se estabelece entre as tecnologias e a educação, uma vez que a simples inserção do computador ou demais tecnologias no espaço escolar não contribui, por si só, em termos de melhorias no ensino e na aprendizagem. Resultados significativos são observados quando o professor, mediador nesse processo, recebe formação e/ou capacitação tecnológica que o assegure o uso criativo e crítico das tecnologias, não apenas para a reformulação de práticas já consolidadas, antes, para o desafio de utilizar estas ferramentas como tecnologias educacionais, enriquecendo o processo de construção do conhecimento, onde o aluno é partícipe ativo (MOLIN, 2010).

\subsection{Rotação por Estações}

O modelo denominado Rotação por Estações é uma metodologia híbrida do modelo menos disruptivo. Tal proposta consiste em dividir a turma em grupos para trabalhar o conteúdo selecionado, disponibilizando materiais didáticos diversos para estimular o desenvolvimento do aprendizado (BACICH; NETO; TREVISANI, 2015). Neste contexto, as tecnologias são utilizadas para trazer maiores possibilidades e enriquecer as atividades desenvolvidas nas estações, sendo também uma importante ferramenta para auxiliar os professores na elaboração de suas aluas. Uma possibilidade para trabalhar um determinado conteúdo neste modelo é - supondo uma divisão da turma em quatro grupos - o de oferecer uma atividade de leitura para o grupo A, enquanto o grupo B assiste a um vídeo, o grupo $\mathrm{C}$ realiza pesquisas 
na internet e o grupo D realiza um experimento prático. É fundamental estimular e compreender o momento de interação dos indivíduos com seu grupo e o seu momento de desenvolvimento do conhecimento de maneira autônoma, pois esta variação é imprescindível para desenvolver não só os conteúdos, mas a autonomia dos alunos. $\mathrm{O}$ professor executa um papel fundamental para viabilizar a gestão deste modelo de maneira satisfatória, pois cabe a ele acompanhar a participação dos alunos e a sua desenvoltura, garantindo suporte e apoio para os alunos que apresentarem quaisquer dificuldades.

\section{METODOLOGIA}

A presente pesquisa foi estruturada visando demonstrar os resultados da utilização do modelo de Rotação por Estações quando aplicados enquanto metodologias didáticas em turmas do ensino fundamental de escolas com recursos tecnológicos limitados. Optou-se por realizar a pesquisa em turma do ensino fundamental devido à carência de estudos com essa temática nesse nível de ensino. Por exemplo, Schiel e Gasparini (2017), após levantamento bibliográfico, identificaram que, em âmbito internacional, $85 \%$ dos artigos relacionados ao Ensino Híbrido estão direcionados ao ensino superior, seguidos de $6 \%$ envolvendo a pósgraduação, 6\% envolvendo o ensino médio e apenas $3 \%$ direcionados às pesquisas no ensino fundamental, dados que expressam a relevância de pesquisas direcionadas à Educação Básica. Assim, a fim de atingir as pretensões explicitadas, a pesquisa de campo foi dividida em três etapas: a primeira, destinada a um curso de formação continuada para professores; a segunda relacionou-se à aplicação da metodologia proposta em sala de aula, através da realização de atividade prática com um professor da disciplina de história em forma de oficina; finalmente, a terceira etapa foi destinada à análise $\mathrm{e}$ discussão dos resultados obtidos nos momentos anteriores.

A primeira etapa ofertou um curso de formação continuada para os docentes da rede pública de ensino, objetivando apresentar aos professores o conceito do Ensino Híbrido e suas propostas metodológicas, assim como incentivá-los e habilitá-los para o uso das mesmas. Neste sentido foram selecionados, dentre o conteúdo programático, tópicos fundamentais para o desenvolvimento da temática, compreendendo conceitos teóricos e práticos.

$\mathrm{Na}$ segunda etapa, após o encerramento do curso, foi oferecido suporte e acompanhamento para que o conceito de Rotação por Estações pudesse ser trabalhado de forma prática na escola, adaptando-o à realidade do professor e de seus alunos.

Este acompanhamento foi ofertado considerando o entendimento de Bacich e Moran (2018) que indicam a necessidade de professores e alunos vivenciarem situações reais de integração e aplicação das tecnologias digitais nos processos de ensino e de aprendizagem para que possam assimilar, de fato, este processo. Neste sentido, considerou-se também o receio e insegurança, evidenciados pelo descompasso usual entre os professores e a apropriação de habilidades para a utilização das tecnologias (MORAN, 2005). Assim, foram selecionados recursos tecnológicos para serem utilizados como material didático alternativo e/ou complementar. Tal seleção foi realizada em conjunto com o próprio docente, considerando os conteúdos que estavam sendo trabalhados naquele momento em sala de aula.

Por fim, a terceira etapa foi destinada à análise dos resultados alcançados e a percepção do professor em relação à oficina realizada. Para compreender a atividade desenvolvida em sala de aula, adotou-se a metodologia qualitativa, onde os métodos adotados foram a observação e a entrevista com o docente responsável pela turma. André e Lüdke (1986) afirmam que este tipo de metodologia é adequada quando a pesquisa realizada recebe influência de seu contexto - neste caso específico, a escola, os recursos, os alunos e professores - e quando se espera obter descrições ricas referentes às situações e às opiniões dos partícipes, considerando também que os dados almejados são gerados e extraídos 
no próprio ambiente de pesquisa, sem que ocorra a interferência do pesquisador.

\section{ESTUDO DE CASO}

\subsection{Curso de formação continuada}

O curso de formação continuada foi ofertado para os professores na própria escola, a ação ocorreu em 3 encontros semanais que, em comunhão com as atividades remotas totalizaram a carga horária de 20 horas. Para atingir os objetivos propostos na metodologia deste trabalho o conteúdo programático do curso abordou tópicos relacionados ao conceito do Ensino Híbrido, as principais propostas metodológicas que compõem o referido conceito além das possibilidades de adaptação e personalizações das atividades, considerando a realidade das escolas, as possibilidades dos professores e as diferentes necessidades dos alunos.

Para o desenvolvimento dos conteúdos foram apresentados vídeos e reportagens sobre a utilização de tecnologias digitais nas escolas, também foram realizadas discussões, reflexões, projeções de problemáticas contextualizadas e pertinentes aquela escola e grupo de professores. Durante o curso foram apresentadas soluções tecnológicas e possibilidades de utilização destas em sala de aula. Dentre tais soluções se encontravam:

- $\quad$ Parâmetros de pesquisa no Google;

- Gerenciador de arquivos (Google Drive);

- Algumas poderosas ferramentas do Google; Testes pelos formulários do Google (criação, execução e análise dos resultados); Google Classroom; Google Arts \& Culture; Google Earth; Seja incrível na Internet;

- Youtube; Como baixar vídeos sem programas e malwares?; Converter e cortar vídeos;

- Canais educativos; Escola Digital; Portal do Professor; Banco Internacional de Objetos Educacionais;

- Mapas conceituais, mapas mentais e diagramas ( coogle);
GoConqr;

4.2 Oficina de História com a utilização da metodologia de Rotação por Estações

A oficina realizada relacionou-se à aplicabilidade da proposta de Rotações por Estações com uma turma do nono ano, composta por vinte e cinco alunos, na disciplina de História. Em encontro com a docente responsável por ministrar a disciplina, discutiu-se e planejou-se a atividade, considerando as características da turma e o tema pretendido para o desenvolvimento da mesma: o conteúdo Guerra Fria. Neste encontro também ficou definido que a professora utilizaria, como critério avaliativo, em ocasião posterior, uma atividade em grupo utilizando mapas mentais. Tal atividade teria como objetivo mensurar os conteúdos absorvidos pelos alunos, numa perspectiva menos restrita e, portanto, mais abrangente de avaliação.

$\mathrm{Na}$ data escolhida para o início das atividades a professora disporia de dois tempos de aula, totalizando 1 hora e 40 minutos. Neste sentido, a proposta de planejamento do encontro contemplava vinte minutos para uma breve introdução do conteúdo, dez minutos para explicar aos alunos como a atividade seria desenvolvida e setenta minutos para que os cinco grupos formados, compostos de cinco alunos cada, alternassem pelas cinco estações propostas.

Considerando que a sala de aula não dispunha de acesso à internet, que a escola não possuía notebooks disponíveis para a execução da atividade e que disporíamos de apenas dois destes aparelhos para utilização, buscou-se analisar e aplicar criticamente os recursos disponíveis, objetivando valorizar e enriquecer ao máximo as atividades realizadas nas cinco estações. Assim, as estações disponibilizaram, consecutivamente, os seguintes materiais didáticos: - $\quad 1^{\circ}$ estação: nesta estação não se utilizou recurso tecnológico, antes, pretendeu-se valorizar e explorar o material tradicional, o livro didático, compreendendo a relevância deste no cotidiano dos alunos;

- $\quad 2^{\circ}$ estação: por meio de notebook, apre- 
sentou-se o vídeo intitulado "GUERRA FRIA: O MUNDO BIPOLAR", que retrata, em forma de animação, a referida temática (GUERRA... 2018). Nesta estação as tecnologias digitais foram utilizadas a fim de, a partir de um vídeo dinâmico e interessante, despertar a atenção dos alunos. $\mathrm{O}$ download do vídeo foi realizado anteriormente ao desenvolvimento da atividade, em razão da falta de conectividade com a internet na sala de aula;

- $\quad 3^{\circ}$ estação: esta estação disponibilizou charges desenhadas manualmente em conjunto com tirinhas diversas, retiradas na internet. Nesta estação propôs-se harmonia entre recursos tradicionais (imagens/desenhos), e mateiras alternativos, como as tirinhas, que apesar da origem virtual, foram impressas anteriormente para se adaptar ao ambiente offline das salas de aula;

- $\quad 4^{\circ}$ estação: a quarta estação dispunha manchetes de jornais e revistas referentes à temática proposta, sendo estas: "O que foi a Guerra Fria?" (INTERESSANTE, 2011), "25 anos do Muro de Berlim" (ESTADÃO, 2014) e "A casa caiu para o comunismo: marreta abre buraco no muro" (PAULO, 2014). Nesta estação as tecnologias foram utilizadas de maneira indireta, não estando presentes no momento da atividade, mas servindo previamente como fonte de pesquisa de materiais com riqueza de detalhes, permitindo aos alunos visualizarem imagens, como por exemplo, do Muro de Berlim em seu estado original, durante o conflito e após a queda. Além das imagens do Muro, as reportagens utilizadas exibiam manchetes noticiadas nos jornais da época;

- $\quad 5^{\circ}$ estação: a última estação disponibilizou uma versão adaptada do quiz (jogo de perguntas e respostas) "Guerra Fria Básico", composto de onze questões (CUCA, 2018). Tornou-se necessário adaptar o quiz, convertendo-o em uma apresentação do software Power Point, considerando que a falta de internet não permitia o acesso ao quiz pela página da web em que o mesmo se encontra disponibilizado.

Apesar da readequação do formato de apresentação do jogo todas as funcionalidades foram mantidas, como a conferência instantânea do resultado, a possibilidade de retornar a pergunta (nos casos de erro) e possíveis explicações ao final de cada pergunta. Nesta estação utilizou-se um segundo notebook para a reprodução do quiz.

$\mathrm{Na}$ data prevista para a realização da atividade nem todos os alunos estavam presentes, alterando a composição da turma para vinte sujeitos. Considerando este novo panorama optou-se por uma readequação nas estações, reduzindo seu número final para quatro estações - unificando a terceira estação (quadrinhos diversos) e a quarta estação (manchetes de jornais e revistas), permitindo aos alunos maior disponibilidade de tempo para apreciarem e analisarem os diferentes materiais, receber suporte da professora e conversar com os demais componentes do grupo sobre a temática.

Aoficinaocorreuconformeoplanejado; os alunos absorveram a essência da atividade e todas as estações operaram sem maiores dificuldades.

No encontro seguinte, a professora realizou a atividade em grupo utilizando os mapas mentais. Mapas mentais estão relacionados a uma forma de organização e armazenamento de informações, utilizando-se, para tal, palavras e/ou imagens. Belluzzo (2006, p. 86) afirma que os mapas mentais permitem "superar as dificuldades de organização da informação e alguns bloqueios da escrita linear", constituindo-se representações de "fácil visualização e memorização." Diferentemente dos mapas conceituais - que requerem a apreensão de um conceito para a compreensão de outro - os mapas mentais são "associações livres de palavras, imagens, cores, números, enfim, tudo o que vier à mente do sujeito a partir de um estímulo inicial" (MOREIRA, 2010, p. 70).

Assim, a aula foi iniciada com a professora discorrendo e esclarecendo alguns pontos em que os alunos demonstraram maior dificuldade de assimilação durante a realização da proposta de Rotações por Estações. Em seguida, a professora explicou aos alunos, de maneira sucinta, o conceito e objetivo dos mapas mentais, instruindo-os sobre o desenvolvimento da atividade. 
Os alunos foram orientados no sentido de que, apesar das diretrizes apresentadas para o desenvolvimento dos mapas, não existia uma única resposta correta, devendo inserir no mapa todos os conceitos e ideias que puderam abstrair/aprender sobre o tema durante a realização da oficina. Os mapas mentais produzidos permitiram observar que, apesar da inexperiência dos alunos com a técnica, os grupos conseguiram expressar diversos conceitos associados à Guerra Fria.

Após a execução das duas atividades que compuseram a oficina de História, elaborada sob a proposta de Rotação por Estações, a professora respondeu a uma entrevista para expressar sua percepção acerca da metodologia em questão e da utilização dos mapas mentais no processo de avaliação.

\section{RESULTADOS E DISCUSSÕES}

A análise da oficina compreende a percepção da professora em relação ao desenvolvimento da atividade. Os dados que embasam esta análise são provenientes de uma entrevista composta de oito perguntas respondidas pela professora ao final da oficina.

Pelas respostas apresentadas pela professora foi possível perceber que a mesma considerou válida a adoção da metodologia proposta, pontuando que o modelo de Rotações por Estações proporcionou reais contribuições para o processo de aprendizagem de seus alunos. Segundo a professora, a oficina potencializou a autonomia dos alunos em relação ao desenvolvimento dos conteúdos, corroborando com as concepções de Bacich, Neto e Trevisani (2015) e Bacich e Moran (2018) em relação à educação pautada nos modelos ativos e híbridos. Os autores ratificam a ideia de que a integração de tecnologias digitais na educação deve ocorrer de maneira criativa e crítica, de modo que favoreça e estimule a autonomia dos alunos, atribuindo a esses caráter protagonista no processo de aprendizado, indo além da função estática de "receptores de informação". Nesta perspectiva, a integração das tecnologias digita- is na educação também vai ao encontro das concepções de ensino apontadas por Freire (1996) e Travi et al. (2009), que criticam a atuação passiva dos alunos frente à construção do conhecimento, com um modelo de sala de aula centrado na figura do professor.

A professora também destacou a importância de iniciativas de formação continuada para os docentes, no sentido de mantê-los atualizados em relação às questões relacionadas à educação e às tecnologias, assim como De Lima e Medeiros (2015) e Leal e Dos Santos (2016), que destacam a necessidade de que os professores desenvolvam conhecimentos acerca das novas tecnologias e formas de aplicações contextualizadas. Tal necessidade, de acordo com a professora respondente, foi suprida durante o curso.

Pôde-se concluir que as atividades desenvolvidas com base na metodologia de Rotações por Estações, assim como também descrito na pesquisa de CANNATÁ (2017), podem ser realizadas em escolas com infraestrutura limitada. Tal limitação tecnológica, apesar de não impedir a aplicação da proposta, exige, em contrapartida, que os professores busquem alternativas e soluções criativas para viabilizar a atividade, considerando que neste modelo não é necessário que todos os alunos estejam utilizando os recursos digitais de forma simultânea. Diante de tal contexto, a metodologia de Rotações por Estações se apresentou como acessível para professores que estão iniciando a exploração das metodologias híbridas.

$\mathrm{Na}$ parte final da entrevista abordou-se a utilização de mapas mentais como alternativa no processo avaliativo. Neste sentido, a professora considerou a utilização dos referidos mapas como recurso interessante e inovador, que contribuiu de forma significativa para a construção do conhecimento dos alunos na atividade proposta, destacando ainda que a adoção da prática estimula a autonomia dos alunos e a compreensão dos conteúdos. Marques (2008, p. 33) afirma que "um mapa mental permite visualizar todas as informações relevantes para um assunto no mesmo campo visual." Moraes et al. 
(2017, p.3-4) asseguram que "os mapas mentais e conceituais são potencialmente recursos do fazer pedagógico, possível de ser trabalhado de forma mais simples e clara para os estudantes. São tipicamente ferramentas de aprendizagem ao sintetizar e estruturar o conhecimento".

É de suma importância mencionar que, nem a professora regente, nem os alunos, haviam desenvolvido quaisquer atividades anteriores que envolvessem a utilização de mapas mentais. Neste contexto, ainda que constituísse objeto da dissertação em questão uma análise aprofundada sobre as potencialidades dos mapas mentais como ferramentas avaliativas, observou-se que a partir da elaboração dos mesmos, os alunos conseguiram expressar diversos conceitos relacionados à temática proposta na oficina. O resultado desta atividade vai ao encontro dos resultados obtidos na pesquisa de Oliveira (2006). Tal pesquisa, realizada no nível de educação básica, recorreu aos mapas mentais em uma perspectiva relacionada à educação ambiental, mensurando a percepção dos indivíduos acerca de questões associadas ao espaço onde estes se encontravam inseridos. A título de conclusão do trabalho, Oliveira (2006) identificou, através do uso dos mapas mentais, que os indivíduos que participaram da pesquisa, de modo geral, demonstraram consciência das dificuldades associadas às questões ambientais tratadas durante a atividade.

Também não constituiu propósito da presente pesquisa discorrer acerca dos processos avaliativos vigentes, todavia, como salienta Bacich, Neto e Trevisani (2015), faz-se necessário, nos dias de hoje, ressignificar tais processos, para além do método classificatório e dicotômico de "certo e errado", "aprovados e reprovados". Nesse sentido, a utilização dos mapas mentais constitui-se possibilidade de enriquecimento do processo de avaliação tradicional, como relatado pela professora durante a entrevista. Este recurso permitiu que a mesma realizasse uma análise sobre os aspectos assimilados pelos alunos e também contribuiu para a identificação das principais dificuldades e/ou conceitos equivocados, o que possibilitou avali- ar se as atividades realizadas foram suficientes para que os alunos compreendessem, de modo satisfatório, a temática em questão.

Repensar o processo avaliativo em consonância com o modelo de ensino híbrido ainda constitui-se desafio. Em relato de experiência ocorrida no ano de 2014, com alunos do $8^{\circ}$ ano de uma escola municipal do Rio de Janeiro, o professor buscou, através da utilização de questionários, verificar o nível de assimilação do conteúdo dos alunos após o primeiro contato com o tema, buscando, a partir daí, personalizar o modo como o conteúdo seria trabalhado em sequência (BACICH; NETO; TREVISANI, 2015). Apesar da inserção de tecnologias no processo de exposição dos conteúdos, a forma de avaliação utilizada no relato (questionários) ainda repercute modelos tradicionais. Nesse sentido, os mapas mentais poderiam apresentarse como possibilidade para a substituição dos questionários, ampliando e subjetivizando as variadas formas de avaliação.

De modo geral, é possível dizer que a apropriação da técnica de elaboração dos mapas mentais pelos professores e a utilização da mesma nos processos de construção do aprendizado e avaliação não demanda maiores complexidades, ao contrário, professores e alunos devem ser apresentados, instruídos e orientados para que possam compreender e praticar o processo de ensino e aprendizagem de maneira mais abrangente, enriquecendo e potencializado tal processo. Como destacado pela professora regente, iniciativas de formação continuada de professores podem contribuir significativamente nesse sentido.

\section{CONCLUSÕES}

Considerando as atividades que compuseram o presente trabalho, torna-se imprescindível destacar a importância de personalizar tais iniciativas de formação continuada, contextualizando as dificuldades e tecendo, em comunhão com os docentes, uma visão crítica na busca de possíveis soluções para as problemáticas vigentes em cada realidade escolar, principalmente no que tange à infraestrutura, como 
a ausência de laboratórios, equipamentos e internet. Sob esse aspecto, a aplicabilidade da metodologia Rotação por Estações, proposta no Ensino Híbrido, apresentou benefícios em sua aplicabilidade, considerando que a maioria dos alunos demonstrou interesse, motivação e participação ativa durante a realização da oficina. Outro fator de relevância observado durante a execução da oficina foi a praticidade para a realização das atividades, considerando que não existem maiores complexidades para a adoção e aplicação deste modelo, possibilitando que mesmo professores com menos desenvoltura em relação à utilização de ferramentas tecnológicas possa recorrer a esta metodologia híbridas com sucesso. Esta premissa se justifica devido à percepção de que os professores não necessitam dispor de conhecimentos técnicos aguçados para adentrarem às experiências pautadas nas metodologias híbridas; o que se requer é que estes profissionais assimilem e compreendam o funcionamento de tais metodologias, o que os cursos de formação continuada podem oferecer.

Apesar de se tratar de uma proposta acessível aos professores de escolas com recursos técnicos restritos, não deve-se desmerecer a importância do suporte de profissionais habilitados para os professores nas primeiras experiências práticas. Tal acompanhamento constitui-se fundamental para que os docentes se sintam seguros diante de uma nova realidade, o que contribuirá para a mudança de percepção em relação ao potencial das ferramentas tecnológicas.

\section{REFERÊNCIAS BIBLIOGRÁFICAS}

ANDRADE, Ana Paula Rocha de. O uso das tecnologias na educação: computador $e$ internet. Trabalho de Conclusão de Curso (Licenciatura em Biologia). Consórcio Setentrional de Educação à Distância. Universidade de Brasília e Universidade Estadual de Goiás. 22f., 2011.

ANDRÉ, Marli; LÜDKE, Menga. Abordagens qualitativas de pesquisa: a pesquisa etnográfica e o estudo de caso. In: ANDRÉ, M.; LÜDKE, M. Pesquisa em educação: abordagens qua- litativas. São Paulo: Ed. EPU, 1986.

BACICH, Lilian; MORAN, José. Metodologias ativas para uma educação inovadora: uma abordagem teórico-prática. Penso Editora, 2018

BACICH, Lilian; NETO, Adolfo Tanzi; DE MELLO TREVISANI, Fernando. Ensino híbrido: personalização e tecnologia na educação. Penso Editora, 2015.

BELLONI, Maria Luiza. Educação a distância e inovação tecnológica. Trabalho, educação e saúde, v. 3, n. 1, p. 187-198, 2005.

BELLUZZO, R. C. B. O uso de mapas conceituais e mentais como tecnologia de apoio à gestão da informação e da comunicação: uma área interdisciplinar da competência em informação. Revista Brasileira de Biblioteconomia e Documentação. Nova Série, São Paulo, v.2, n.2, p.78-89, dez. 2006.

CANNATÁ, VERÔNICA. Ensino Híbrido na Educação Básica: narrativas docentes sobre a abordagem metodológica na perspectiva da personalização do ensino. Dissertação (Mestrado em Educação). Universidade Metodista de São Paulo. 153f., 2017.

CUCA, Racha. Guerra Fria: Básico. Quiz. Disponível em: <https://rachacuca.com.br/ quiz/8596/guerra-fria-basico/>. Acesso em: 06 nov. 2018.

DE LIMA, ANDRÉIA LUCIMAR SILVA; MEDEIROS, LIZIANY MÜLLER. O Lúdico na Formação de Professores da Educação Básica na Capacitação em TIC. INFORMÁTICA NA EDUCAÇÃO: teoria \& prática, v. 19, n. 3, p. 81-93, 2016.

ESTADÃO, Acervo. 25 anos da queda do Muro de Berlim: 'Estado' cobriu fatos marcantes nos 28 anos de existência do muro: da construção à derrubada. 2014. Disponível 
em: <https://acervo.estadao.com.br/noticias/ acervo,25-anos-da-queda-do-muro-de-berlim,10549,0.htm>. Acesso em: 14 nov. 2018.

FREIRE, Paulo. Educação "bancária" e educação libertadora. Introdução à psicologia escolar, v. 3, p. 61-78, 1996.

GUERRA FRIA: O MUNDO BIPOLAR QUER QUE DESENHE? | DESCOMPLICA. Produção de Descomplica. 2018. (8 min.), son., color. Série Quer que desenhe?.

INTERESSANTE, Super. O que foi a Guerra Fria?: Conflito não teve guerra entre os dois rivais. Mas seus aliados pegaram em armas por todo o século 20. 2011. Disponível em: $<$ https://super.abril.com.br/mundo-estranho/oque-foi-a-guerra-fria/>. Acesso em: 14 nov. 2018 .

Jordão, T. C. (2009). Formação de educadores: A formação do professor para a educação em um mundo digital. In BRASIL. Ministério da Educação. Secretaria de Educação a Distância. TV Escola. Boletim Salto para o Futuro: Tecnologias Digitais na Educação. Brasília,

DF: MEC/SEED, 9-17. LEAL, Andreza Cristiane Silva; DOS SANTOS, Edna Capacitação Docente para o uso das Novas Tecnologias. 2016.

LOUREIRO, Carla Cristiane; GRIMM, Viviane; LUNARDI-MENDES, Geovana M. "Imigrantes" versus "Nativos" Digitais: O discurso de Tecnologias Digitais em Políticas Curriculares. Roteiro, v. 41, n. 3, p. 725-742, 2016.

MARQUES, António Manuel de Miranda. Utilização pedagógica de mapas mentais e de mapas conceptuais. Dissertação (Mestrado em Expressão Gráfica, Cor e Imagem). Universidade Aberta. 153f., 2008.

MOLIN, S. I. L. Novas Tecnologias na Educação: Transformações da Prática Pedagógica no Discurso do Professor. Dissertação (Mestrado em Educação). Universidade do Vale do Itajaí, Santa Catarina, 133f., 2010. MORAES, Márcia Amaral Corrêa et al. Mapas Mentais como significação do conhecimento: um estudo de caso aplicado à Educação Infantil. In: IV Congresso Nacional de Educação: CONEDU, 2017.

MORAN, José Manuel. A integração das tecnologias na educação. Salto para o Futuro, v. 204, 2005.

MOREIRA, Marco Antonio. Mapas conceituais e aprendizagem significativa. São Paulo, Centauro, 2010.

OLIVEIRA, Leonardo Araújo. O Rizoma e a Metáfora do Hipertexto: sobre a educação e a (s) estrutura (s) do conhecimento no pólo mediáticoinformático. Anagrama, v. 6, n. 1, p. 1-12, 2012.

OLIVEIRA, Nilza Aparecida da S. A educação ambiental e a percepção fenomenológica, através de mapas mentais. REMEA-Revista Eletrônica do Mestrado em Educação Ambiental, v. 16, p. 32-46, 2006.

Paulo 2014

SCHIEHL, Edson Pedro; GASPARINI, Isabela. Modelos de Ensino Híbrido: um mapeamento sistemático da literatura. In: Anais do XXVIII Simpósio Brasileiro de Informática na Educação, p. 1-10, 2017.

SCHIEHL, Edson Pedro; KEMCZINSKI, Avanilde; GASPARINI, Isabela. As Perspectivas de Avaliar o Estudante no Ensino Híbrido. RENOTE, v. 15, n. 2, 2017.

STEINERT, Monica Érika Pardin; DE BARROS, Marcelo Paes; PEREIRA, Mirtes Campos. O Descompasso Entre Ensino Híbrido e Digital Divide: Docentes de Ciências da Natureza em Foco. Revista de Ensino, Educação e Ciências Humanas, v. 17, n. 3, p. 209-215, 2016. 
TRAVI, Marilene Gonzaga Gomes; OLIVEIRA-MENEGOTTO, Lisiane Machado de; SANTOS, Geraldine Alves dos. A escola contemporânea diante do fracasso escolar.Rev. psicopedag., São Paulo, v. 26, n. 81, p. 425-434, 2009 . Disponível em $<$ http://pepsic.bvsalud. org/scielo.php?script $=$ sci_arttext\&pid $=\mathrm{S} 0103$ $84862009000300010 \& \operatorname{lng}=\mathrm{pt} \& \mathrm{nrm}=\mathrm{iso}>$. acessos em 21 set. 2017. 